\title{
A dinâmica da baraka no mausoléu de Sidi 'Ali ben Hamdouche, Marrocos
}

\author{
The dynamic of the baraka in the \\ mausoleum of Sidi 'Ali ben \\ Hamdouche, Morocco
}

\begin{abstract}
Bruno Ferraz Bartel
Doutorando em Antropologia - PPGA/UFF Integrante do Instituto de Estudos Comparados em Administração de Conflitos INCT - InEAC Núcleo Fluminense de Estudos e Pesquisa - NUFEP Núcleo de Estudos do Oriente Médio - NEOM brunodzk@yahoo.com.br
\end{abstract}


Resumo: O presente artigo visa explorar a noção de baraka como um fenômeno religioso dinâmico quanto à sua identificação e localização como fonte de poder. $\mathrm{O}$ foco será a contextualização das atividades relativas ao circuito de peregrinação a uma tumba de santo, localizada em uma vila rural próxima da cidade de Meknes, no Marrocos. Diferente da tese de que a baraka se irradiaria a partir de determinado lugar (santuário) em concentrações cada vez menores, centrada apenas na presença física e material do corpo do santo, meu argumento é de que a baraka poderia ser manipulada simbolicamente, tendo como base a participação dos descendentes dos santos na transmissão da baraka. O objetivo dessas ações, como pretendo demonstrar, visa garantir períodos de reestruturação interna ao grupo religioso que comanda o santuário, ao mesmo tempo em que expõe determinados laços políticos com o governo marroquino, sobretudo a partir das novas dinâmicas de poder atuante sobre os mausoléus do país.

Palavras-chave: Baraka; Santos; Marrocos.

Abstract: This article explores the notion of baraka as a dynamic religious phenomenon as to its identification and location as a source of power. The focus will be on the context of activities related to pilgrimage circuit to a saint's tomb, located in a rural village near to Meknes, Morocco. Unlike the thesis that baraka radiates from a particular place (sanctuary) into few concentrations, focused only on physical presence and stuff of the holy body, my argument is the baraka can be manipulated symbolically by those who are responsible and controllers of these sites by the creation of a new space of devotion based on the participation of the descendants of the saint in the transmission of baraka. The purpose of these actions, as I intend to demonstrate, is proposed to guarantee internal restructuring periods to the religious group who orders the sanctuary, while I try to expose certain political relations with the Moroccan government, especially from the new dynamics of power acting on the mausoleums over the country.

Keywords: Baraka; Saints; Morocco. 
A noção de baraka é usualmente representada na religião islâmica como uma força (benção) capaz de provocar prosperidade material, bem-estar físico, satisfação corporal, plenitude ou até mesmo sorte (CHELHOD, 1955; CRAPANZANO, 1973; DENFFER, 1976; DOUTTÉ, 1909; EICKELMAN, 1985; GEERTZ, 2004; MUNSON JR, 1993; PETERS, 1989; RAUSCH, 2000; WESTERMARCK, 1968). Uma visão sobre o assunto remonta ao período do protetorado francês (1912-1956) no país, que fez referências interpretativas ao termo baraka como sendo fonte de poder associada a lugares, objetos e indivíduos dotados de santidade (CORNELL, 1998; GELLNER, 1969). O termo santidade procura expressar as noções de proteção ou de intercessão na vida dos indivíduos (wilaya) e a de alguém próximo de Deus (walaya). Diante desse contexto, pode-se concluir que essa força ou potência religiosa equivaleria a uma benção e que poderia ter efeito miraculoso na vida de quem entra em contato com a pessoa ou coisa que a possui (CORNELL, 1998).

Uma das formas de aquisição de baraka é a realização de uma peregrinação (ziyara, pl. ziyarat) ao túmulo (qbar, pl. qbour) de um santo (wali, pl. awliya). A ziyara equivale à experiência da peregrinação a um local sagrado, ou seja, um santuário. A ziyara é um ato necessário que manifesta o reconhecimento e a fidelidade de parte da sociedade ao santo, que valida e confirma seu contra dom a partir da noção de baraka. Na região do Magreb (Marrocos, Sahara Ocidental, Argélia e Tunísia), o culto aos santos adquiriu notoriedade a partir de ideias e histórias concretas de determinados lugares (santuários), ritos específicos, circuitos de peregrinações e, inclusive, festas vinculadas a essas personalidades (DOUTTÉ, 1900a, 1900b; DERMENGHEM, 1954). No Marrocos, a temática do culto aos santos tem provocado intensos debates nas produções acadêmicas acerca das características desse fenômeno religioso (CORNELL, 1988; GELLNER, 1969; HAGOPIAN, 1964; MARCUS, 1985). A presença de baraka se constitui como elemento indispensável dessas dinâmicas religiosas no Norte da África, visto que o quadro dos agentes sociais responsáveis por esses contextos são complexos e apresentam particularidades bem delimitadas.

O presente artigo visa explorar a noção de baraka como fenômeno religioso dinâmico suscetível de levantar questões quanto à identificação e localização dessas fontes de poder. O foco será a delimitação das atividades relativas ao circuito de peregrinação à tumba de um santo, localizada em uma vila rural próximo da cidade de Meknes, no Marrocos. Diferente da tese de que a baraka se irradia a partir de um 
determinado lugar (santuário) em concentrações cada vez menores (GIBB, 1999), a partir da presença física e material do corpo do santo, meu argumento é que a baraka pode ser transmitida pelos responsáveis que controlam esses locais por meio da criação de novo espaço de devoção que conte com a participação dos descendentes dos santos na transmissão da baraka. O objetivo dessas ações, como pretendo demonstrar, seria garantir períodos de reestruturação interna do grupo ${ }^{2}$ religioso que comanda o santuário, ao mesmo tempo em que evidenciaria determinados laços políticos com o governo marroquino, sobretudo a partir das novas dinâmicas de poder relativas aos mausoléus do país.

De modo geral, algumas das definições islâmicas de ritual, relíquias e de territórios sagrados são responsáveis por delimitar noções de autoridade ${ }^{3}$ e, por conseguinte, de estrutura da ordem social vigente através de sistemas complementares atuantes (WHEELER, 2006). No caso das tumbas de santo no Marrocos, elas se tornam fundamentais para as discussões que envolvem poder político e religioso a partir das lógicas das peregrinações existentes no país (BRUNEL, 1926; CRAPANZANO, 1973; NABTI, 2010). A capacidade miraculosa de um santo adquire significado a partir das múltiplas narrativas acionadas tanto por peregrinos quanto por seus descendentes, principalmente quando é possível interpretar suas hagiografias ${ }^{4}$.

Um ponto fundamental sobre a origem dessas formas de autoridade no Marrocos reside na crença de que a santidade de alguns homens adviria da linha de descendência direta com o profeta Mohammed (DRAGUE, 1951). Neste sentido, a importância dos túmulos dos santos na lógica das peregrinações possibilita indicar as motivações por parte dos indivíduos em obter ou, pelo menos, entrar em contato com baraka. Não é minha intenção aqui realizar um inventário sobre como o termo foi interpretado na região do Magreb. Mesmo assim, cabe salientar que algumas das definições de baraka propostas por determinados autores permitirá repensar as possibilidades dos modelos já desenvolvidos em contraste com as observações de minhas pesquisas etnográficas.

O termo baraka adquiriu um valor equivalente a benção a partir da intervenção de Deus (CRAPANZANO, 1973; RAUSCH, 2000). Complementar a essa noção, a força presente em homens e em lugares sagrados possibilitaria a obtenção de tal dádiva (GELLNER, 1969; WESTERMARCK, 1968). A discussão em torno de como a baraka 
afetaria a vida dos indivíduos tem sido abordada historicamente pelo prisma do marabutismo, ou seja, refere-se ao reconhecimento de uma santidade que seria hereditária (através do sistema de genealogias ligadas ao profeta Mohammed), responsável pela revelação das evidências portadoras de baraka existentes em alguns homens tidos como santos. Neste caso, as teses vinculadas à capacidade dos santos de mobilizar os circuitos de peregrinações adquirem uma centralidade no contexto da região a partir da valorização dos processos de legitimação de poder (entendida como carisma por muito tempo) por intermédio dessas figuras religiosas.

Os modelos de carisma que envolvem a noção de santidade podem ser ordenados em dois eixos: 1) karamat (produção de eventos miraculosos) e 2) baraka (benção divina). É através dessas duas vertentes que se torna possível a realização de atos extraordinários no cotidiano dos indivíduos, ao mesmo tempo em que se evocam as capacidades de produção de fenômenos tidos como sobrenaturais. A organização dessa estrutura através das genealogias (sistema de linhagens) dos santos e os esforços na demonstração desses poderes como atividades ligadas ao plano divino atestam o funcionamento desse modelo (DOUTTÉ, 1909; BOUBRIK, 1999).

Cabe salientar que a trilha construída a partir da perspectiva da virtude do santo como uma fonte de baraka, envolvendo a projeção de um carisma pessoal, encontra-se presente na obra seminal de Clifford Geertz (2004). Este autor propõe analisar a sua concepção, mais particularmente a marroquina, a partir da relação entre o divino e o mundano, ou seja, entre as intercessões do espiritual com o material. O papel de uma autoridade moral, que somente a figura da santidade teria condições de evocar, é o que daria ao projeto do marabutismo presente no Marrocos a sua face estrutural para o surgimento de uma fonte de poder ligada a uma personalidade sagrada. Neste sentido, a noção de baraka convergiria para a noção de centro exemplar, de força atuante na vida dos indivíduos.

Entretanto, a virtude das personalidades ditas sagradas (noção que Geertz não esclarece muito bem) é tida como um dom, inerente. O problema, seria, então, definir quem o teria, o quanto seria associado a ele e como seria possível alguém se beneficiar dele. Assim, a imagem formada a partir desta concepção presente no Marrocos apresenta-se muitas vezes uniforme e atrelada a uma história onde o termo baraka é apresentado como monolito intocável. Na dinâmica desses processos que envolvem a 
fonte de poder das santidades marroquinas, Geertz narra uma história coerente, mas a partir de uma cultura (unidade de significados) estática dentro da produção dos limites de seu próprio contexto histórico, que teria forjado a maioria de suas interpretações sobre o país (GHOULAICHI, 2005).

Em outra perspectiva para o problema da relação entre santidade e autoridade no Marrocos, Vincent Cornell (1998) aponta para uma crítica às abordagens neoweberianas acerca do tema da santidade na religião islâmica. $O$ autor se refere explicitamente ao modelo weberiano de autoridade carismática. Nos estudos sobre o Marrocos, esse conceito é comumente empregado para explicar o fenômeno da hereditariedade da santidade. No lugar do profeta, a partir do tipo-ideal weberiano do líder carismático, os neo-weberianos colocam a figura do marabout (homem devoto a Deus, capaz de exercer autoridade sentimental sobre as pessoas), enquanto o carisma é substituído por baraka (CORNELL, 1998).

De acordo com a teoria de Weber sobre a transformação do carisma, a autoridade carismática de um líder religioso se dilui após a sua morte em um carisma hereditário que passaria a residir em seus descendentes. Mas para preservar essas posições no mundo, a segunda e terceira geração de líderes carismáticos necessitaria criar meios dos quais a prova de seus efeitos miraculosos e demais feitos mágicos pudessem continuar a atrair clientes. Desde que o carisma puro não pode ser mantido por muito tempo, a autoridade hereditária dependerá do contexto de sua estrutura econômica e social. Essa rotina (rotinização) do carisma facilita a criação de aspectos de autoridade carismática somente a algumas poucas gerações futuras. Uma vez estagnada, a religiosidade legítima das lideranças assume formas de autoridade tradicional, que possui escassas conexões com suas formas anteriores.

Esta pesquisa integra um período de 11 meses de trabalho de campo entre os meses de janeiro-novembro de 2012 e janeiro de 2015, na vila de Sidi 'Ali (distrito de Mrhassiyine), localizada na província de Meknes-Tafilalet, no Marrocos. A vila rural de Sidi 'Ali possui uma história ligada ao nome de seu santo fundador (Sidi' Ali ben Hamdouche) e está localizada a $18 \mathrm{~km}$ da antiga capital imperial marroquina de Meknes. A pesquisa etnográfica privilegiou tanto o circuito de peregrinações ${ }^{5}$ ao mausoléu de Sidi 'Ali ben Hamdouche quanto as ações dos descendentes do santo (tariqa Hamdouchia) que controlam o acesso a este santuário. O termo tariqa (pl. turuq) indicava um método 
gradual envolvendo o que se denominou de misticismo contemplativo entre os adeptos do sufismo a partir da reunião de um círculo de discípulos sobre a tutela de um mestre $\left(\right.$ shayk $\left.h^{6}\right)$.

$\mathrm{Na}$ vila de Sidi 'Ali, os peregrinos podem optar por visitar três lugares específicos: 'Ayn Kabir (a fonte de água onde se realizam as purificações corporais), a gruta de Aisha Qandisha ou o próprio mausoléu de Sidi' Ali ben Hamdouche. Afirmo não existir uma sequência fixa que defina uma ordem de visitação desses lugares, assim como tampouco a necessidade de que se vá a todos eles, ao longo da peregrinação. A viagem, inclusive, pode prosseguir para outras rotas existentes nas montanhas de Jebel Zerhoun, como a vila de Sidi Musa (santo local) ou a cidade de Moulay Idriss (primeira capital imperial do Marrocos).

Para quem pode dedicar os finais de semana ou parte do período de férias em Sidi 'Ali, a vila dispõe de três hotéis com capacidade média de 100 pessoas cada. Geralmente a opção mais comum aos visitantes consiste em se utilizarem de um quarto coletivo onde podem passar as noites na companhia de 3 a 6 pessoas. Quartos individuais são raros nos hotéis. Algumas casas (de 2 a 3 andares) estão disponíveis para serem alugadas. Alguns moradores locais também disponibilizam espaços internos de suas residências para o recebimento de novos hóspedes, quando a capacidade dos hotéis chega ao seu limite. Isso ocorre durante os períodos de intensa visitação à vila, como no caso do Mawlid alNabawi (celebração do Aniversário do Profeta).

O método que fundamentou as minhas interpretações foi o da observação direta, que consiste no envolvimento do pesquisador nas atividades do grupo social no qual esteja inserido a fim de que possa apreender os princípios conceituais e ações rituais que organizam as experiências dos interlocutores. A maioria das entrevistas do trabalho de campo foi conduzida em francês justamente por falta de domínio do árabe coloquial marroquino (darija). Desta língua, eu dominava apenas o vocabulário religioso e algum conhecimento dialetal para a realização de conversas informais. Em raras situações, foi possível utilizar uma comunicação em espanhol com os marroquinos, visto que esta língua se encontra mais presente no norte do país. Em outros casos, recorri também à língua inglesa.

Em termos práticos, isso significa que eu visitava, com a devida autorização, o 
mausoléu do santo junto com os peregrinos, assim como em suas demais atividades realizadas por eles (compra dos artigos religiosos nas lojas disponíveis), durante a construção do ritual de peregrinação na vila. Eu também frequentava a casa de alguns dos descendentes de Sidi 'Ali para ter acesso às conceituações acerca de como eles analisavam a importância do santuário na dinâmica da vila. Além disso, muitas das conversas que pude presenciar, entre os descendentes do santo, explicitavam algumas das práticas recorrentes na preservação da estrutura religiosa local, assim como nas estratégias criadas pela tariqa Hamdouchia na manutenção de sua posição social perante os moradores locais e peregrinos.

\section{O contexto histórico no Marrocos e a importância do sufismo}

O Marrocos contemporâneo é marcado pela diversidade em sua composição étnica e religiosa e conta com uma população estimada em 32 milhões de habitantes. Em termos de etnicidade, a população marroquina é composta, em sua maioria $(99,1 \%)$, por árabes $(69.5 \%)$ e berberes (29.6\%), além de imigrantes vindos dos demais países da África e da Europa, totalizando um percentual de $0,9 \%$. No campo da religiosidade, cabe destacar a presença de uma minoria de judeus $(0,2 \%)$ e de cristãos $(1.1 \%)$. No entanto, a população é predominantemente ligada ao islamismo sunita (98.7\%) (NJOKU, 2006).

Processos históricos dos mais diversos se fazem presente na região desde o século VII quando a religião islâmica foi introduzida através das conquistas árabes. Um panorama social pode auxiliar na indicação de alguns elementos presentes até hoje na vida religiosa da população marroquina. Tal tarefa pode sugerir uma digressão ao longo do tempo, mas a intenção aqui é apenas situar o contexto da produção das experiências religiosas na vila de Sidi' Ali.

A consolidação do malikismo, como guia de orientação na forma do Islã constitutivo da região ao longo do século VII, estabeleceu as bases para os grupos sociais que teriam acesso ao poder durante os séculos XI e XII, além da formação dos governos subsequentes. Fundado por Malek ibn Anas (711-795), o malikismo é uma das mais antigas escolas (das quatro existentes) relativa às jurisdições islâmicas. Ela admite que o julgamento individual dos estudiosos (teólogos e juristas) pode intervir em uma parte da realidade social através de uma pesquisa para a prática do bem comum. Portanto, o malikismo é conhecido por adaptar as regras islâmicas aos costumes e 
contextos locais. Entretanto, somente a partir da dinastia dos Almôada (1124 -1269), estabelecida no Marrocos no século XII e consolidado ao longo do século seguinte, é que o território pôde presenciar o desenvolvimento de uma elite e de um conjunto de instituições religiosas capazes de converter substancialmente a população ao Islã (LAPIDUS, 1988). Nesse sentido, o papel do sufismo (tasawmuf) foi fundamental como força religiosa atuante sobre o destino da região devido ao seu papel político na configuração de um campo social marcado por relações de tensões a partir das disputas de poder. Tal fato impulsionaria mais tarde a formação do território que viria a ser o Marrocos.

O sufismo, dentro da tradição religiosa do Islã, pode ser definido como a busca de uma experiência direta com Deus (BALDICK, 1989; EVANS-PRITCHARD, 1949; SCHIMMEL, 1975; TRIMINGHAM, 1971). Essa meta é considerada como a expressão de um processo longo de iniciação realizado por um indivíduo através de um caminho ou via mística (tariqa), sob a orientação de um shaykh. A base dessas experiências religiosas é induzida por performances rituais e o caminho Sufi não consiste em uma trajetória religiosa completamente intersubjetiva sem a produção de constrangimentos externos, pois exige que cada estado religioso (hal) experimentado pelo indivíduo esteja de acordo com as doutrinas e práticas transmitidas pelos textos, rituais e ensinamentos orais que compõem as diferentes tradições Sufis (PINTO, 2002; 2005).

A necessidade de uma avaliação da própria experiência religiosa faz com que o mestre (shaykh) apareça como um elemento fundamental no caminho Sufi, porque somente aqueles que tiveram uma experiência direta com a realidade divina (haqiqa) podem guiar os demais na busca de um caminho rumo a Deus (PINTO, 2002; 2010). De acordo com a tradição Sufi, o conhecimento religioso tem duas dimensões: uma exotérica (zabiri), que deriva da percepção sensorial do mundo material, e outra esotérica (batini), que é atingido através de uma relação experiencial com a realidade/verdade divina (haqiqa). O caráter experiencial do caminho Sufi significa que seu conhecimento se torna encarnado em pessoas que tenham atravessado essas experiências e que sua transmissão é praticada através da orientação e do exemplo de vida do mestre. Portanto, a relação mestre/discípulo entre os Sufis e seu shaykh fornece a estrutura sobre a qual as experiências são construídas e expressas (HAMMOUDI, 1997; PINTO, 2002). 
Três ramos constituem os pilares Sufis entre as confrarias ou ordens marroquinas. A Chadilia fundada por Iman Chadili (1193 - 1278), a Qadiria fundada por Moulay Abdelkeader Jilali (1077 - 1166) e a Tidjania fundada por Sidi Abmed Tijani (1735 1815). A partir das duas primeiras, existem outras ramificações tornando cada vez mais complexo o quadro das instituições religiosas marroquinas. No Marrocos, as diversas ordens ou confrarias Sufis fazem parte de um quadro não só importante do ponto de vista da organização religiosa, mas também no plano da política. Diversos indivíduos ligados a essas confrarias ocupam cargos do governo direta ou indiretamente através de sua relação com a monarquia marroquina (DARIF, 2010). Em alguns casos, uma confraria pode ganhar maior projeção dentro da sociedade através da conversão de intelectuais ou artistas que, através do uso da imagem da via mística associada ao sufismo, contribuem para fortalecer um projeto de expansão do grupo, como o que acontece na tariqa Qadiria Boutchichia (DALLE, 2007).

A confraria Hamdouchia, cuja história remonta ao ramo da Chadilia no Marrocos e que me serviu como espaço de interlocução inicial no cenário da vida religiosa da vila de Sidi 'Ali, exerce influência política na província de Meknes-Tafilalet. Alguns de seus membros que visitam periodicamente a vila de Sidi'Ali se encontram ligados a algum cargo burocrático exercido na prefeitura de Meknes ou até mesmo na capital do país (Rabat). Ainda que atualmente a vila seja alvo de um longo debate sobre a questão da sucessão ${ }^{7}$ na tariqa, a influência da Hamdouchia é determinada pela produção agrícola (azeitonas, óleo de azeitona e criação de animais) na região, além de uma rede política urbana estruturada a partir das mais diversas zamiyas ${ }^{8}$ espalhadas pelas cidades no Marrocos e fora dele?.

\section{Santidade e sufismo no Marrocos: um exemplo a partir da Hamdouchia}

Cornell (1998) observou uma multiplicidade de crenças e práticas rituais constitutivas do Marrocos desde o período de introdução do Islã no século VII na região do Magreb, sob a forma de um sufismo mais orientado para um pietismo (primazia do sentimento na experiência religiosa) do que de uma forma de pensamento metafísico (teologia racionalista) produzido somente por autoridades religiosas. A consequência disso seria atestada pela autoridade exercida pelos santos (awliya) através dos valores por eles suscitados na população local. Nesse sentido, a ideia de uma santidade associada a 
personalidades dotadas de poder (baraka) se torna fundamental para compreender este processo religioso no país.

A noção de santidade envolve não só proximidade com a presença Divina (walaya), mas também o exercício de uma autoridade mundana (wilaya). Este último termo se refere à relação entre um mestre (shaykh) e seus adeptos (murid), enquanto a primeira noção é usada para descrever sua relação com Deus. São esses dois aspectos interligados (wilaya e wilaya) que dão ao shaykh seu status numa comunidade religiosa como agente divino apto a guiar seus discípulos tanto nas questões religiosas quanto nas questões que envolvem a política. Ambos os aspectos (mundano e religioso) são qualidades constitutivas da noção de santidade. Cabe destacar que a dicotomia entre poder secular e religioso, na constituição do modelo de autoridade no contexto marroquino, é uma divisão artificial para indicar como se entrelaçam as relações políticas e religiosas no país. Além disso, o status de cada shaykeh é confirmado pela capacidade de fazer milagres (karamat) perante sua comunidade religiosa, o que coloca a questão da prova (rotinização da baraka), constante entre os Sufis.

A confraria Sufi marroquina Jazuliyya, por exemplo, como analisou Cornell (1998), usou a doutrina segundo a qual os santos seriam os herdeiros dos profetas e uma personificação universal da realidade vivida pelo profeta Mohammed (tariqa Mobammedia) para justificar o envolvimento das ordens Sufis na vida política do país. Neste sentido, podese afirmar que diversos grupos puderam formar parte da elite religiosa nos territórios que viriam a ser o Marrocos. Mais tarde, o resultado disso seria a imbricação dessas estruturas religiosas com o regime político do sultanato ${ }^{10}$.

Os santos no sufismo seriam uma denominação para determinados homens que possuiriam os seguintes atributos: 1) descendência da família do profeta Mohammed; 2) portador de poderes (baraka) entre seus devotos, sobretudo por meio de milagres (karamat); e 3) um modo de vida exemplar, que muitas das vezes expressa determinadas virtudes morais (GELLNER, 1969). Seja como for, a figura dos santos é responsável pela produção de um discurso de poder e de autoridade configurando assim a sua forma de organização na estrutura do sufismo marroquino (CORNELL, 1998).

A confraria Hamdoucbia encontra-se ligada à figura de Sidi 'Ali ben Hamdouche (1666 - 1722), responsável pela constituição do que hoje assume a forma de uma vila 
rural (distrito de Mrbassiyine localizada na província de Meknes-Tafilalet) encravada nas montanhas de Zebel Zerboun. Sua história remonta a de uma personalidade envolvendo práticas devocionais amplamente reconhecidas como virtuosas, além da demonstração de diversos milagres (karamat) ao longo de sua vida. A genealogia de Sidi 'Ali ben Hamdouche $^{12}$ faria parte, segundo os interlocutores da confraria Hamdouchia, da linhagem direta dos descendentes do profeta Mohammed no Marrocos, denominada de shurfa (sing. sharif).

Esse termo foi usualmente utilizado pelas mais variadas confrarias Sufis existentes no país através da ideia de que a linhagem desses homens garantiria o acesso e a distribuição de baraka. Tal fato se verifica no plano da política quando se observa que o status proveniente de uma determinada shurfa confere a certos indivíduos posição de prestígio na sociedade marroquina. Não é por acaso que a monarquia atual (dinastia Alauíta) também se encontra representada nessa genealogia (sistema de linhagens ${ }^{13}$ ) que a liga diretamente ao profeta Mohammed.

Desse modo, torna-se evidente como religião e política encontram-se mutuamente implicadas no contexto marroquino. Geertz (2004) esboçou um modelo em que se reconhece uma série de conflitos entre os produtores de ordem e de rebelião no campo social do Marrocos através do mito da atuação de homens santos, reconhecidos por sua veemente devoção a Deus (leia-se baraka como carisma religioso) e ousadia ao desafiar ações injustas por parte do sultão (autoridade política). Os séculos XVII e XVIII seriam marcados pela expansão do marabutismo a partir desse modelo, o que justificaria a cooptação e incorporação de muitas dessas linhagens de homens santos para o quadro da shurfa marroquina. 


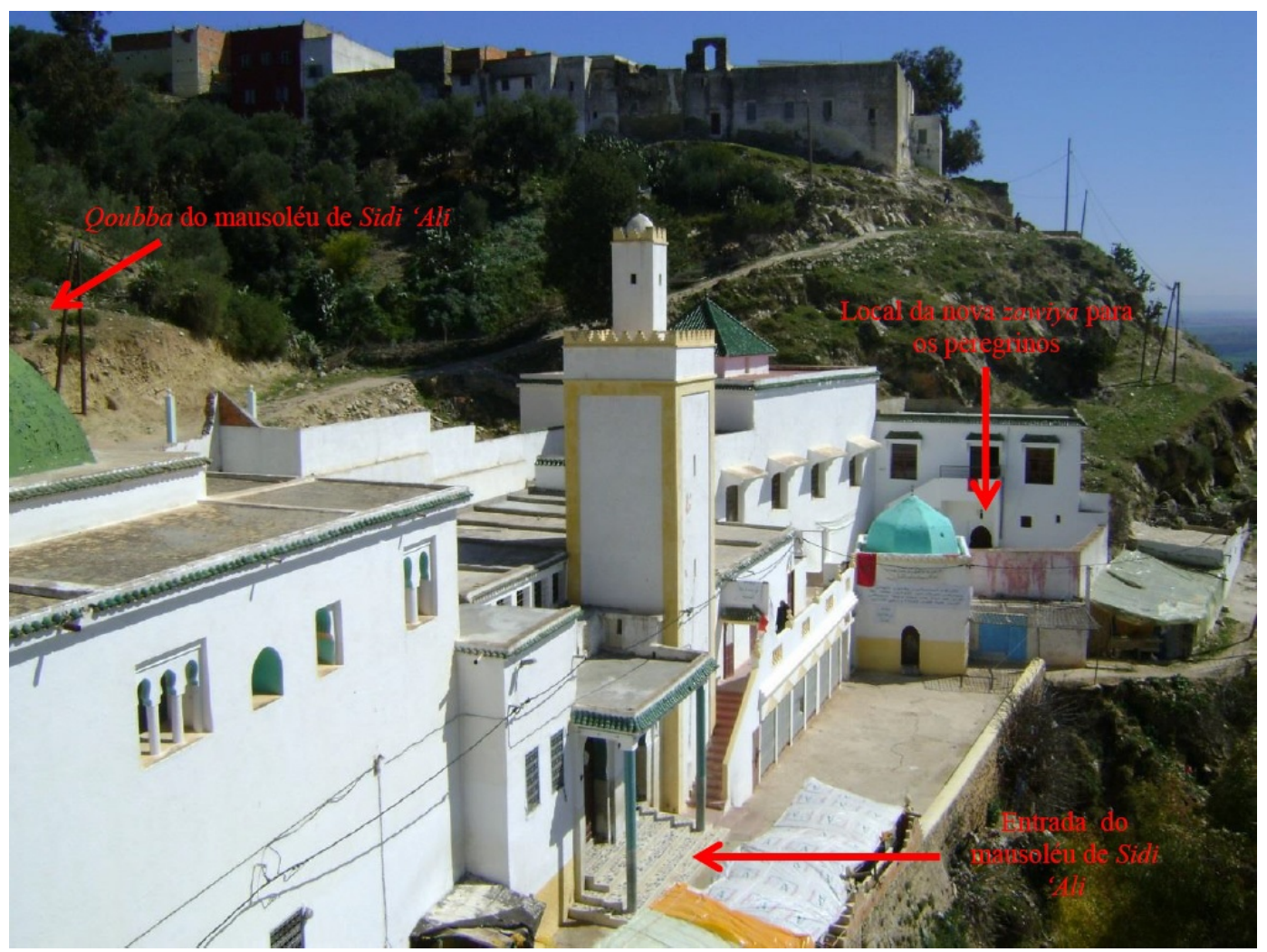

Foto 01 - Panorama do mausoléu de Sidi 'Ali ben Hamdouche. Foto do autor. Março de 2012.

Esse modelo religioso tanto atesta a reputação de determinados homens enquanto pertencentes a uma ordem sagrada, onde Geertz (2004) nunca explicitou a constituição dessa ordem, como parece ser o caso dos santos, quanto proporciona também a exclusão de outras linhagens de santidade no plano da política marroquina. Quando me refiro à reputação ou a exclusão desses homens tidos como santos, isso deve ser remetido não ao carisma desenvolvido por parte deles, mas sim ao grau de poder e autoridade investidos neles e em seus descendentes (CORNELL, 1998). Entretanto, cabe salientar que muitos desses homens santos e seus descendentes não irão se constituir em uma organização religiosa nos moldes de uma instituição Sufi tradicional.

A busca pelo reconhecimento dessas linhagens por parte dos descendentes dos santos junto às instâncias políticas marroquinas dá-se por meio de um conjunto de práticas populares ainda atuantes, como no caso das peregrinações, além da capacidade de dispor de relíquias e objetos religiosos nos espaços visitados pelos peregrinos. Caso contrário, essas linhagens podem se perder ao longo do tempo. Um exemplo disso se encontra presente na vila de Sidi 'Ali. Nos arredores das montanhas de Jebel Zerhoun, 
estão localizadas as cinco qoubbas (estrutura em forma de cúpula que indica a presença de um túmulo) de santos com pouca expressividade de culto visto a condição de abandono e de destruição parcial dessas estruturas. Esses santos não exercem qualquer papel relevante na lógica de peregrinação existente na vila, uma vez que a dinâmica religiosa local encontra-se voltada para o seu principal santo: Sidi' Ali ben Hamdouche.

Somente o discípulo mais famoso de Sidi 'Ali, Sidi Ahmed Dghoughit, é capaz de atrair peregrinos ao seu mausoléu (localizado a $2 \mathrm{~km}$ da vila de seu mestre), justamente porque esta prática faz parte de um ciclo ritual que se inicia em Sidi 'Ali pelos peregrinos. Isso acontece porque tanto Sidi 'Ali ben Hamdouche quanto Sidi Abmed Dghoughi se constituem nas principais figuras da tariqa Hamdouchia, popularmente difundida e legitimada pelo poder político-religioso no Marrocos. Quanto aos demais santos locais, eles não chegam a ter expressividade de culto na província de Meknes-Tafilalet, devido ao poder concentrado pelos descendentes desses dois santos sobre as atividades (religiosas e agrícolas) da região.

\section{As narrativas sobre Sidi 'Ali ben Hamdouche e seus usos na vila}

Os relatos que envolvem o santo fundador da vila (Sidi' Ali ben Hamdouche) são os mais recorrentes no imaginário de seus descendentes, moradores locais e peregrinos. $\mathrm{O}$ mito descreve que Sidi 'Ali após sair da Universidade de Qarawiyyin ${ }^{15}$, localizada na cidade de Fez (a $25 \mathrm{~km}$ de Meknes), teria decidido morar nas montanhas de Jebel Zerhoun para levar uma vida exemplar baseada nas prescrições das escrituras islâmicas (no caso, o Alcorão $^{16} \mathrm{e}$ os Hadiths $^{1}$ ). A partir desse isolamento, voltado para o estudo do Islã, Sidi 'Ali teria alcançado reconhecimento como modelo de virtude na aplicação das práticas da religião no cotidiano e, consequentemente, teria se tornado um homem dotado de poderes (baraka).

A montanha, além de ser um elemento contemplado em diversas passagens do Alcorão, é tida como o local mais próximo de Deus segundo os moradores locais. Ainda segundo o mito local, Sidi 'Ali organizou sua vida nas encostas de Jebel Zerhoun por muitos anos a partir de suas práticas monásticas específicas (caminhadas, orações próximas a fontes d'água e a recitação ${ }^{18}$ dos nomes de Deus). Conforme o tempo passava, o conhecimento de Sidi' Ali sobre a religião islâmica somente aumentava, o que lhe garantiu o acesso ao poder (baraka) vindo de Deus e a materialização de milagres 
(karamat), na vida das pessoas através de seu contato.

Uma história circulante na vila, principalmente entre os moradores locais, descreve que a aquisição de baraka por Sidi 'Ali teria se dado por meio de Bou Rabid Echaki $i^{19}$, um homem reconhecido por sua reputação religiosa. O mito narra que Bou Rabid Echaki teria adoecido durante uma viagem que realizava com seus quarenta discípulos pelas montanhas de Jebel Zerboun. Enquanto aguardava sua recuperação, Bou Rabid Echaki decidiu realizar um teste entre os discípulos em 'Ayn Kabir, uma fonte d'água que marca um dos pontos iniciais da construção da vila de Sidi' Ali.

Após discursar perante todos os presentes no local, Bou Rabid Echaki teria indagado a seus adeptos quem poderia tomar a água que ele havia reservado em um copo, dotada de propriedades poderosas. Todos os seus discípulos se recusaram ante a constatação da saliva deixada no copo por Bou Rabid Echaki. Entretanto, Sidi 'Ali ben Hamdouche, que passava pelo local, não titubeou ante o desafio proposto. Bebeu do copo até o fim e foi embora em silêncio. Horas depois, Bou Rabid Echaki viria a falecer, deixando todo seu poder (baraka) para Sidi' Ali.

O mesmo modelo de transmissão de baraka, porém com detalhes diferenciados quanto a suas formas, foi exposto por Geertz (2004) no final dos anos de 1960, para traduzir o fenômeno do marabutismo no Marrocos. Anos mais tarde, Vincent Crapanzano (1973) registrou outras versões desse mesmo episódio em outros grupos ${ }^{20}$ religiosos (no caso, a Hamadsha) devotos a Sidi 'Ali. Seja como for, a tariqa Hamdouchia continua a explorar essas histórias de aquisição de baraka quando se trata de justificar a preservação do mausoléu do santo (datado do século XVII) junto aos peregrinos.

As visitações ao mausoléu de Sidi 'Ali garantem uma renda financeira aos descendentes do santo ao longo do ano, visto a quantidade de peregrinos oriundos das mais variadas partes do país ao santuário. As doações ao mausoléu podem ocorrer na forma de dinheiro, depositado em um baú de madeira (sodoq), ou na forma de oferendas (garrafas de água de rosa, velas, incensos, pães e até tapetes) aos responsáveis do dia pelo local. Além disso, os comércios provenientes das lojas existentes na vila (roupas, calçados e artigos religiosos dos mais diversos), onde inclusive muitos descendentes são os proprietários, garantem os demais fluxos monetários internos da tariqa. 
Entre alguns de meus interlocutores ${ }^{21}$, Mobammed (35 anos, solteiro e comerciante) é dono de uma dessas lojas há oito anos, desde o falecimento de seu pai. Sua relação com os peregrinos que visitam o local dá-se estritamente no plano comercial, porque, segundo Mobammed, muitos de seus produtos disponíveis acabam nem sendo direcionados para a peregrinação à Sidi ' $A l^{22}$. Rachid (45 anos, casado e agricultor de azeitonas) é dono de um hotel ${ }^{23}$ que serve de estadia para muitos peregrinos. Ele procura desenvolver laços sociais com alguns de seus frequentadores visto a recorrência dos mesmos indivíduos ou grupos de pessoas a cada novo ciclo de atividades na vila. Em resumo, esses dois exemplos acabam por evidenciar os graus de envolvimento e de participação de cada descendente de Sidi' Ali na dinâmica religiosa a partir do sistema de peregrinação local.

Além disso, muitos peregrinos são responsáveis por atualizar ou expandir os temas de transmissão de baraka contidos nas narrativas míticas. 'Ayn Kabir, a fonte d'água próxima ao mausoléu de Sidi 'Ali, e que não é controlada pela tariqa Hamdouchia, serve como ponto nodal no circuito de peregrinação por se destacar como local de passagem donde os peregrinos buscam levar consigo galões de água de até cinco litros, extraídos dos córregos. Muitos se utilizam dessa água para beber, cozinhar ou tomar banho, ${ }^{24}$ a partir da crença de que a baraka do santo pode facilitar a realização de desejos (formação de casamentos, fertilidade feminina, busca por empregos) ou mesmo a cura para doenças.

Uma marroquina (Nádia, 40 anos, desempregada) visitou o local com seu marido francês ('Ali, 32 anos, vendedor) de família marroquina. Ela estava motivada a visitar 'Ayn Kabir pela terceira vez para agradecer seu recente casamento e também para conseguir residir na França, o que, segundo ela, só seria possível por meio do contato com baraka. Quanto a seu marido, tudo era novidade. Foi, inclusive, sua primeira vez na vila de Sidi'Ali.

Após lavar seus cabelos em um dos córregos de 'Ayn Kabir, Nádia virou-se para a direção da nascente e agradeceu a Sidi 'Ali por sua eficácia. Em seguida, ela pagou o equivalente a 10 dirhams $^{25}$ (1,20 dólares em 2012) para um dos responsáveis pelo local (um não descendente do santo) em troca de um galão de cinco litros de água do córrego. Ela disse que levaria a água para beber e para cozinhar em sua casa, reconhecendo valor terapêutico em suas propriedades. "E quando acabar este galão, eu volto de novo. Quem 
sabe agora com um filho nos braço" (N.; entrevista, 17/09/2012), concluiu a peregrina sorrindo. Neste sentido, o ato da peregrinação (ziyara) permite o contato com novas formas de benções (baraka) e o reforço das anteriores por intermédio do santo.

Cabe destacar que novos usos e símbolos religiosos são incorporados e mobilizados pelas motivações as mais diversas ${ }^{26}$, à dinâmica religiosa da vila. Todavia, a tariqa Hamdouchia exerce um controle sobre os tipos de práticas (preces e orações em horários estabelecidos) assim como sobre os objetos ofertados no mausoléu (dinheiro, garrafas de água de rosa, velas, incensos, pães e tapetes). Tais ações procuram evitar os desvios ( bid' $^{\prime}$ ) das formas tradicionais ${ }^{27}$. Neste sentido, as ações dos descendentes de Sidi 'Ali cumprem um papel fundamental na definição da noção de baraka do santo e tornam seu acesso somente possível através dessas formas de poder e de autoridade sobre o sistema de peregrinação vigente no mausoléu.

\section{A interdição da tumba de Sidi' Ali e a nova qawiya para os peregrinos}

Desde que iniciei minhas investigações em 2012 na vila de Sidi 'Ali durante o Mawlid al-Nabawi (celebração do Aniversário do Profeta), parte do mausoléu encontrase fechado para obras de reparo em suas estruturas internas. Segundo a tariqa Hamdouchia, o risco de desabamentos por causa do mau estado de conversação, especialmente nas áreas que levam à tumba do santo, poderia colocar em risco a vida das pessoas. $\mathrm{Na}$ época, eu pude visitar internamente o mausoléu com alguns descendentes do santo e comprovar a necessidade dessas restaurações a partir da quantidade de estacas de madeira e de andaimes metálicos existentes, que fixam parte do teto em alguns desses recintos.

Essas contenções foram realizadas por engenheiros contratados pelo Ministério de Habous e de Assuntos Islâmicos ${ }^{28}$ que, desde o ano de 2010 segundo a tariqa Hamdouchia, tem se proposto a firmar um acordo de restauração do local como parte da nova política do governo de Mohammed VI (no poder desde 1999), de apoio às estruturas religiosas que formariam um patrimônio histórico no país. Apesar do discurso de preservação deste santuário fundado no século XVII, em meu retorno ao local em 2015 não observei mudança na paisagem da vila. Entretanto, tal situação não inviabiliza a ida de peregrinos ao local. 
Diante da impossibilidade de patrocinar a reforma completa do mausoléu, a tariqa Hamdouchia optou por transformar uma antiga sala de orações (mussala) em uma nova zawiya para receber os peregrinos (ver sua localização na foto 01). As duas portas do mausoléu, que serviam de entrada aos visitantes para a tumba de Sidi 'Ali, agora são altares para o depósito de oferendas (garrafas de água de rosa, velas, incensos e, até mesmo pães), além do recolhimento de dinheiro em pratos de palha ( $\left.t^{\prime} b a g\right)$ sob responsabilidade de alguns descendentes do santo. Neste sentido, cabe destacar a escolha de determinados indivíduos com funções bem definidas neste primeiro local de contato com os peregrinos que visitam o mausoléu.

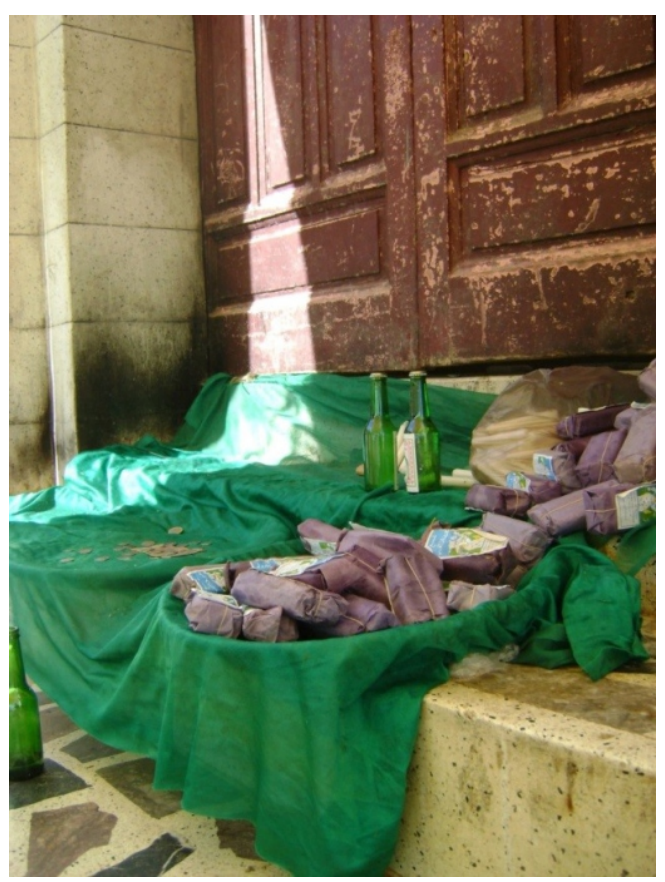

Foto 02: Oferendas nos portões do mausoléu de Sidi' Ali ben Hamdouche. Diante da impossibilidade de visitar a tumba do santo, velas, garrafas de água de rosa, incensos e até mesmo pães são depositados nos degraus. A utilização de um tecido verde sobre a escadaria do mausoléu (cor por excelência da religião islâmica e presente na cobertura da maioria das tumbas dos santos no Marrocos) fornece um espaço para a demonstração pública das intenções dos peregrinos em suas atividades religiosas no local. Foto do autor. Setembro de 2012.

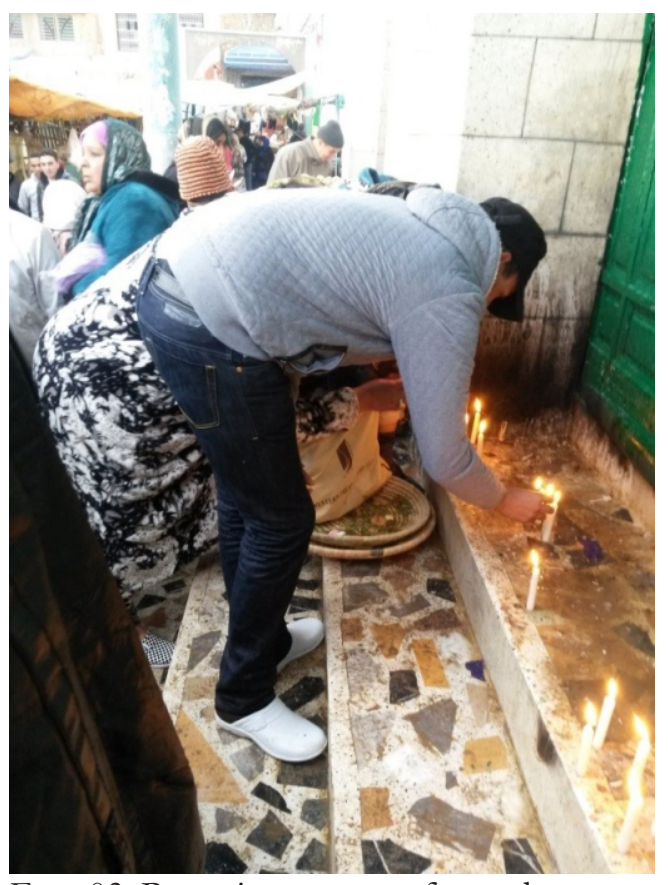

Foto 03: Peregrinos e suas ofertas durante o Mawlid al-Nabawi (celebração do Aniversário do Profeta). Foto do autor. Janeiro de 2015. 
Esses homens, ocasionalmente, ocupam uma posição de estudiosos e conhecedores do Alcorão (fqi ${ }^{29}$, pl. fuqaha) junto aos visitantes, auxiliando-os durante a peregrinação ao mausoléu. Após a entrega de dinheiro ou dos objetos tradicionais da peregrinação (ziyara) ao santo, preces podem ser requisitadas pelos peregrinos ao fqib como forma de reforçar seu pedido por baraka, assim como marcar sua intenção no cumprimento do ciclo ritual de visitas ao santuário. Porém, há indivíduos que não se satisfazem em apenas deixar suas oferendas e seus votos na entrada do mausoléu. Para esses peregrinos, a tariqa Hamdouchia organizou uma nova zawiya para indicar que a baraka do santo pode residir em outros espaços, além do acesso da tumba interditada.

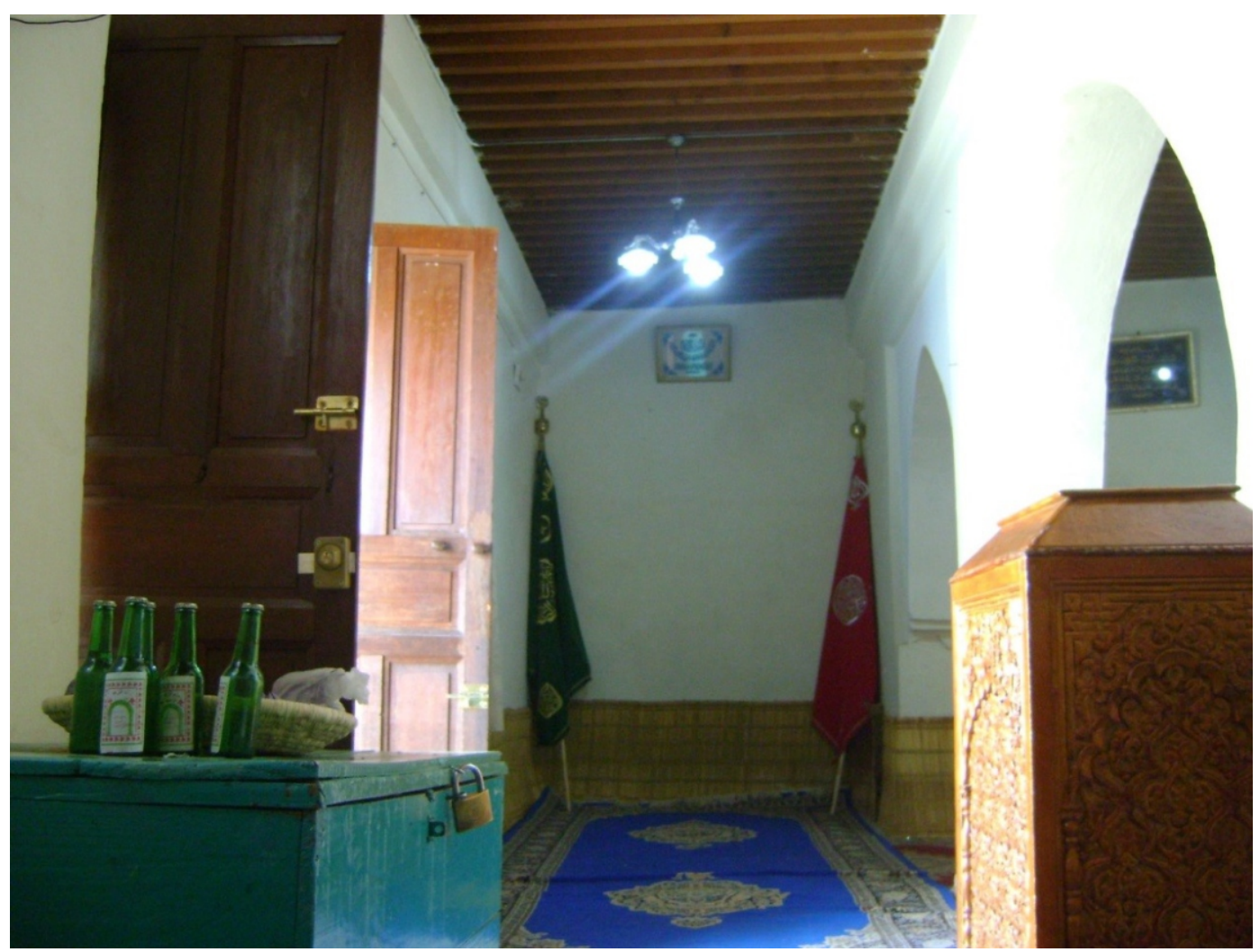

Foto 04 - Interior da mussala transformada em zamiya para a recepção dos peregrinos. Note a existência de baús que recebem dinheiro (o da direita) e objetos (o da esquerda), bem como garrafas de água de rosas, velas, incensos e até mesmo pães. Ao fundo, duas bandeiras da Hamadsha, um grupo que possui vínculos identitários de murid (discípulo / devoto) de Sidi 'Ali ben Hamdouche. Foto do autor. Abril de 2012.

Quem opta por seguir as escadas do mausoléu passa por uma área que contém a lápide de oito descendentes da tariqa Hamdouchia até chegar à nova ramiya. Logo na entrada o peregrino se depara com dois baús: o primeiro (sodoq), onde seu dinheiro pode 
ser depositado, e o segundo, onde o fqih do dia recebe os objetos ofertados por ele. Diferente do que acontece nas portas do mausoléu, os peregrinos procuram sentar-se e acomodar-se (muitos, inclusive, dormem), permanecendo no recinto bastante tempo para entrar em contato com a presença do santo.

A impossibilidade de se ter acesso à tumba do santo não implica perda de baraka por parte dos peregrinos. Ela está garantida justamente pela presença de três descendentes de Sidi' Ali no recinto, os quais se revezam na recitação do Alcorão, durante o período de visitações. Além disso, parte dos visitantes demandam preces a esses homens, em troca de pagamento em dinheiro, para que eles intercedam na distribuição da baraka proveniente de Sidi' Ali.

Haja (35 anos, casada, dona de casa e residente de Meknes) visitou a zamiya acompanhada de seu marido $A b d e l$ (40 anos, funcionário da prefeitura). Era a quarta vez que se encontravam em Sidi 'Ali desde que se casaram em 2006. Haja fazia a peregrinação com o intuito de engravidar. O casal permaneceu na zawiya por cerca de 20 minutos, sentado no chão, conversando entre si. Em um momento, Haja estendeu as mãos, em formado de conchas rente ao corpo, e recitou uma prece a Sidi 'Ali. Abdel estava confiante na baraka do santo a partir de suas doações junto aos descendentes. Antes de saírem, Haja deu o equivalente a 20 dirhams (2,50 dólares em 2012) ao fqih do recinto e pediu-lhe que uma prece fosse a ela direcionada.

A nova zawiya parece atender as demandas dos peregrinos que visam ter contato direto com o santo mesmo que seu local original se encontre interditado. Os descendentes do santo usam a estratégia de recitar uma quantidade de preces em conjunto sempre que são acionados, sobretudo a partir das doações em dinheiro. As sequências das preces muitas vezes expõem a temática da aquisição da baraka presente nas narrativas de Sidi 'Ali como meio de materializar os pedidos dos visitantes. Além disso, a escolha da tariqa Hamdouchia em preservar seus descendentes no novo local garante a presença e circulação de baraka, uma vez que um conjunto de práticas (tempo de permanência, conduta no local e formas de preces) pode ser compartilhada entre descendentes e peregrinos. 


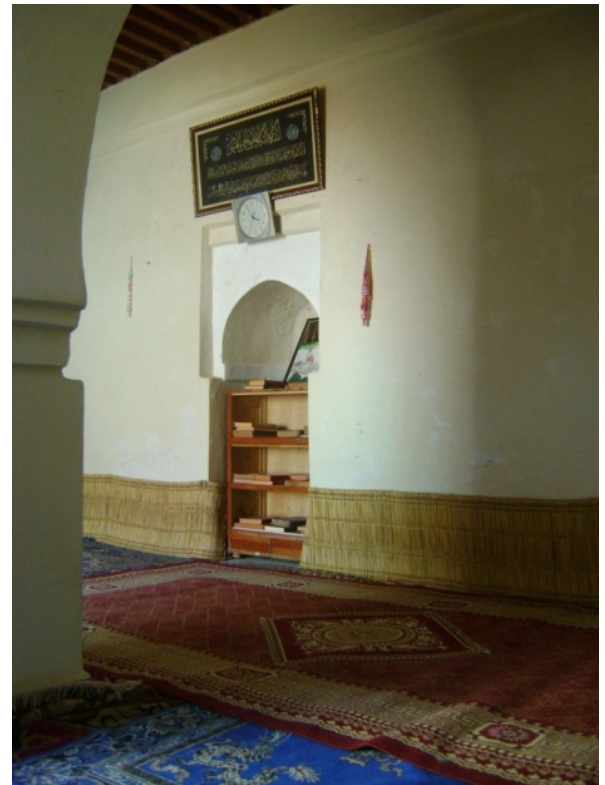

Foto 05 - Interior da mussala transformada em espaço de recepção para os peregrinos. A qibla (local que aponta a direção de Meca) garante o suporte das orações evocadas pelos peregrinos para a obtenção da baraka de Sidi 'Ali. Note que sua estrutura exibe um quadro referente à shahada (frases de testemunho da crença muçulmana), um relógio no auxílio do tempo para a realização das orações e alguns Haddiths (produção textual que contém diversas narrativas sobre a vida do profeta Mohammed). Foto do autor. Abril de 2012.

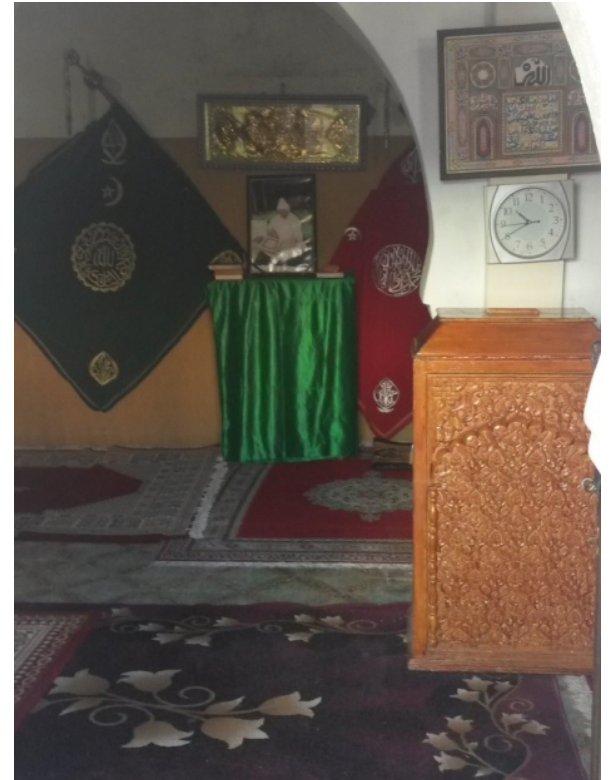

Foto 06: Mudança no interior da mussala transformada em espaço de recepção para os peregrinos. A foto sobre o móvel de madeira ainda exibe o rei do Marrocos (Mohammed VI) lendo o Alcorão. Porém, diversos objetos foram realocados (relógio, velas e tapetes) ou suprimidos, como a qibla durante minha segunda estadia no campo. Foto do autor. Janeiro de 2015.

Durante a segunda visita ao local em 2015, uma mudança espacial realizada pela tariqa Hamdouchia na zawiya chamou minha atenção para o valor dado às preces realizadas pelos descendentes junto aos peregrinos. A qibla (ver foto 05) havia sido encoberta por uma esteira de palha, que corria ao longo das quatro paredes do recinto, ocultando assim dos visitantes sua localização. O móvel de madeira que continha a foto do rei atual do Marrocos (Mohammed VI) lendo o Alcorão foi posicionado à frente da posição antiga da qibla formando uma espécie de altar no recinto. Além disso, as bandeiras da Hamadsha foram realocadas atrás da foto do rei, ocultando completamente as estruturas anteriores da qibla. 
A ideia, segundo alguns interlocutores, foi a de estabelecer um local onde as preces dos peregrinos fossem direcionadas ao santo a partir da contribuição dos descendentes na interseção e circulação da baraka. Assim, o local destinado às orações individuais / coletivas (mussala) passou a ser um local de preces individuais (zaniya) organizada pela presença dos descendentes do santo (shurfa). Neste sentido, o controle existente na dinâmica do mausoléu de Sidi' Ali continuava a atuar através de suas formas tradicionais como o uso do sistema de linhagens que ligam os santos à descendência com o profeta Mohammed.

\section{Considerações finais}

A dinâmica espacial da nova zawiya atende aos interesses da tariqa Hamdouchia na preservação de sua imagem como guardiões da baraka do santo, embora sua relíquia principal (a tumba) se encontre sem acesso público. Diante da impossibilidade de visitas a essa fonte de baraka, a transformação de uma sala de orações (mussala) em um centro ritual (zawiya) não alterou o regime de peregrinação (ziyara) em Sidi' Ali. Neste sentido, não é a existência material do corpo que importa, mas sim a presença da baraka (BOISSEVAIN, 2006). A manipulação de baraka para um segundo local pôde se realizar através da ênfase nas preces realizada pelos descendentes do santo. As peregrinações foram, então, ampliadas a partir dessas ações dos descendentes, que explicitaram a existência e circulação de baraka por meio de suas preces. Com o tempo, a tariqa Hamdouchia acionou as formas tradicionais para o projeto de reestruturação interna do grupo a partir do resgate da noção de santidade vinculada à linhagem direta dos descendentes do profeta Mohammed (shurfa) ainda atuante no Marrocos.

Por fim, mesmo que agravado pelo impasse das obras financiadas pelo governo marroquino na restauração do mausoléu, o Ministério de Habous e de Assuntos Islâmicos não se omitiu diante de outros temas importantes para a tariqa Hamdouchia referentes ao controle de seu santuário. Ao longo dos Mawlid al-Nabawi (celebração do Aniversário do Profeta) que pude observar nos anos de 2012 e 2015, uma estrutura patrocinada pelo governo marroquino garante o acesso seguro aos peregrinos. É comum encontrar guardas rodoviários mobilizados na organização do trânsito das estradas rumo à vila, além de um aparato (carros de bombeiros e ambulâncias) de prevenção a acidentes durante o ciclo de peregrinações à Sidi 'Ali e nas demais localidades ${ }^{30}$ de Zebel Zerboun. 
A finalização de uma nova mesquita ${ }^{31}$ na vila (que segue os modelos arquitetônicos do governo de Mohammed VI) parece ter motivado os descendentes do santo para o início das obras de restauração no mausoléu. Seja como for, a maneira encontrada pela tariqa Hamdouchia para a resolução de seus problemas temporários (como a interdição do mausoléu) foi mediada por formas tradicionais de discurso e práticas religiosas, bem específicas do Marrocos. O controle desse circuito de peregrinação à vila de Sidi 'Ali estabelece um ponto nodal para o projeto de reestruturação interno do grupo.

\section{Notas}

1. Qualquer palavra a ser destacada no corpo do texto e palavras estrangeiras (árabe) aparecerão em itálico.

2. Entendo o termo grupo como equivalente da noção de comunidade elaborada por Max Weber (1968) baseada no sentimento subjetivo de pertencimento dos agentes.

3. Entendo o termo autoridade como o definido por Weber $(2004 ; 1982)$.

4. Entendo as hagiografias como um conjunto de descrições da vida de algum santo (wali, pl. awliya) que visam dar visibilidades as virtudes e as capacidades miraculosas (karamat) desses agentes religiosos.

5. Entendo as peregrinações como processos sociais, ou seja, como fenômenos liminares e que revelam em suas relações sociais a qualidade de communitas (TURNER, 2008).

6. A palavra significa ancião em árabe, sendo um título de respeito usado para designar as autoridades religiosas muçulmanas.

7. A confraria Hamdouchia se encontra sem um shaykh desde 1980, segundo dois interlocutores do grupo que moram na vila de Sidi 'Ali. Desde essa época, o filho do shaykh não conseguiu organizar, sobretudo a partir de sua figura, uma unidade política diante das demais famílias ligadas a confraria. Após sua morte em 2004, coube ao neto do último shaykh a busca, mesmo que minimamente, por seu reconhecimento (autoridade política) entre a maioria de seus associados visando uma cooperação e reestruturação interna.

8. Local ritual ou centro das atividades religiosas ligadas a uma confraria Sufi. Acrescentarei um $s$ no final da palavra para indicar o seu plural.

9. Foi-me relatado por membros da confraria Hamdouchia a presença de zamiyas ligadas a esta confraria religiosa na Argélia e, também, na Tunísia durante meu trabalho de campo.

10. A dinastia Alanita assumiu o poder nos territórios marroquinos em 1664 e, até o presente, governa o país na forma de uma monarquia.

11. A palavra Sidi no Marrocos adquire uma conotação formal que envolve admiração e respeito. Desta forma, essa rubrica é relegada a pessoas reconhecidas por suas virtudes morais em vida, servindo de modelo exemplar para os demais. O termo Lalla se refere às mulheres que possuem esse status.

12. Sidi 'Ali, segundo a confraria Hamdouchia, seria descendente de Idriss I (745 - 791) responsável por trazer o Islã ao Marrocos e de ter fundado a primeira dinastia (Idríssidas) sobre seus territórios.

13. A dinastia Alauíta remonta a história do reinado de Moulay Idriss (788-791), responsável pela primeira dinastia no Marrocos (Idrísidas). Idris I era neto de Hassan, filho de 'Ali e neto do profeta Mohammed.

14. Não tive acesso na vila, nem na forma de documentos, a uma cronologia detalhada referente à vida de Sidi Ahmed Dghonghi. Um dos poucos registros que obtive sobre sua vida é a de que ele estaria ligado, em sua origem, às tribos existentes do Sahara (sul do Marrocos). 
15. Uma das mais antigas universidades do mundo criada por volta no ano de 859 a.d.

16. O Alcorão é o resultado textual da recitação da palavra divina por Mohammed entre os anos de 610 e 632 a.d.

17. Os Hadiths (acréscimo meu do $s$ para indicar o seu plural) são as coleções de tradições sobre a vida do profeta Mohammed registradas por seus companheiros e compiladas após a sua morte ao longo dos anos.

18. Prática denominada de dhikr entre os Sufis.

19. Não tive acesso na vila, nem na forma de documentos, a uma cronologia referente à vida de Bou RabidEchaki.

20. Organizações ou irmandades religiosas (ta'ifa, pl. tawa'if) que tem como característica a filiação (sistema de linhagens) a um santo e a presença de ritmos musicais na execução de ritos particulares. O termo organização expressa a referência a um local particular para os encontros dos membros de um grupo.

21. Preservarei os nomes dos meus interlocutores através de sua substituição por outros. A idade, estado civil, ocupação e residência dos interlocutores atestam para a multiplicidade dos indivíduos que compuseram a pesquisa etnográfica.

22. No caso, muito desses objetos são utilizado ao culto de Aisha Qandisha, uma gênia (jinn, pl.jnun) bastante reconhecida no país. Os jnun são seres invisíveis feitos de fogo e que compõem o universo simbólico da religião islâmica. A palavra jnun no Marrocos é o plural do termo djinn, que também é usado nos demais países que possuem o Islã como código e discurso cultural. Um ser feminino deste tipo recebe, às vezes, a denominação de jinniya.

23. Eu iniciei quase toda a minha pesquisa etnográfica neste local visto a facilidade de se entrar em contato com os visitantes direcionados aos mais variados circuitos de peregrinação na vila.

24. É possível tomar banho em 'Ayn Kabir a partir das três instalações (estruturas de concreto) construídas pelos responsáveis locais mediante um pagamento.

25. Moeda corrente no país representada pelas inicias MAD.

26. O sonho (dimensão onírica), muito das vezes, aparece atrelado aos relatos dos peregrinos como uma justificativa para se realizar a peregrinação.

27. O culto aos santos também é vista como desvio ( bid'a $^{\prime}$ ) por parte de grupos ligados a salafiyya. Esse termo é usado para designar diferentes correntes reformistas que procuravam restaurar o que eles consideravam como o Islã dos precursores/ancestrais (salaf), ou seja, do profeta e seus companheiros.

28. O Ministério de Habous (termo islâmico relacionado à legislação de propriedade da terra) e de Assuntos Islâmicos foi criado pela monarquia marroquina para dotar o governo de um instrumento de execução que fortalecesse sua política religiosa no país. Em realidade, com a criação das duas terminologias, o Estado marroquino adotou uma burocracia religiosa que visa controlar as práticas públicas referido em um sistema de normas oficiais que fixam as condutas e os seus limites que não podem ser transgredidos.

29. O fqib pode assumir três funções distintas. Em primeiro lugar, ele é reconhecido como um jurista para assuntos que envolvem a jurisprudência islâmica como, por exemplo, dúvidas sobre algum aspecto das orações obrigatórias que os muçulmanos devem realizar ao longo dia. Num segundo plano, ele é tido como uma pessoa capaz de recitar o Alcorão através de seu grau de memorização. Ele pode acionar e selecionar trechos das escrituras sagradas para a decodificação do Islã como idioma religioso que deve permear a conduta moral dos indivíduos. Por último, o termo fqib pode remeter à figura do professor ligado as primeiras fases da infância de uma pessoa sendo este o responsável pela alfabetização das crianças em língua árabe e os primeiros ensinamentos da religião islâmica. A primeira forma possui um caráter mais informal (atribuição tradicional) e quanto para as outras duas, apresentam um caráter mais popular nas sociedades islâmicas.

30. Refiro-me refiro principalmente as peregrinações à Moulay Idriss (primeira capital imperial do Marrocos).

31. Em 2012, eu pude presenciar o início dessas obras com membros da tariqa Hamdouchia.

\section{Referências bibliográficas}


BALDICK, Julian. Mystical Islam: an Introduction to Sufism. London: I.B. Tauris, 1989.

BOISSEVAIN, Kátia. Sainte parmi les saints: Sayyda Mannûbiya ou les recompositions cultuelles dans la Tunisie contemporaine. Paris: Maisonneuve et Larose, 2006.

BOUBRIK, Rahal. Saints et societé en Islam. La confrerie ouest saharienne Fadiliyya. Paris: CNRS Éditions, 1999.

BRUNEL, René. Essai sur la confrérie religieuse des Aïssaouas au Maroc. Casablanca: Editions Afrique Orient, 1926.

CHELHOD, Chelhod. La baraka chez les Arabes ou l'influence bienfaisante du sacré. In: Revue de l'histoire des religions, Paris, v. 148, n. 1, p. 68-88, 1955.

CORNELL, Vincent. Realm of the Saint: power and authority in Moroccan Sufism. Austin: University of Texas, 1998.

CRAPANZANO, Vincent. The Hamadsha: a Study in Moroccan Etnopsychiatry. Los Angeles: University of California Press, 1973.

DALLE, Ignace. Maroc: Histoire, société, culture. Paris: La Découverte/Poche, 2007.

DARIF, Mohamed. Monarchie Marocaine et Acteurs Religieux. Casablanca, Afrique Orient, 2010.

DENFFER, Dietrich Von. Baraka as basic concept of muslim popular belief. In: Islamic Studies, v. 15, n. 3, p. 167-186, 1976.

DERMENGHEM, Émile. Le culte des saints dans l'islam maghrébin. Paris: Gallimard, 1954.

DOUTTÉ, Edmond. Magie et religion dans 1'Afrique du Nord. Alger, A. Jourdan, 1909.

. Notes sur L'islam Maghribin: Les Marabouts (Suite). In: Revue de l'histoire des religions, Paris, v. 41, p. 22-66, 1900a.

Notes sur L'islam Maghribin: Les Marabouts (Fin). In: Revue de l'histoire des religions, Paris, v. 41, p. 289-336, 1900 b.

DRAGUE, Georges. Esquisse d'histoire religieuse du Maroc: confréries et zaouias. Paris: Peyronnet, 1951.

EICKELMAN, Dale. Knowledge and Power in Morocco: The Education of a Twentieth Century Notable. Princeton: Princeton University Press, 1985. 
EVANS-PRITCHARD, Evans. The Sanusi of Cyrenaica. Oxford: Clarendon Press, 1949.

GEERTZ, Clifford. Observando o Islã. O desenvolvimento religioso no Marrocos e na Indonésia. Rio de Janeiro: Jorge Zahar, 2004.

GELLNER, Ernest. The Saints of the Atlas. Chicago: University of Chicago Press, 1969.

GHOULAICHI, Fatima. Of Saints and Sharifian Kings in Morocco: Three Examples of Reimagining History through Reinventing King/Saint Relationship. Master's Thesis. College Park, University of Maryland, 2005.

GIBB, Camila. Baraka without Borders: Integrating Communities in the City of Saints. In: Journal of Religion in Africa, London, v. 29, n. 1, p. 88-108, 1999.

HAGOPIAN, Elaine. The Status and Role of the Marabout in Pre-Protectorate Morocco. In: Ethnology, Pittsburgh, v. 3, n. 1, p. 42-52, 1964.

HAMMOUDI, Abdellah. Master and Disciple: The Cultural Foundations of Moroccan Authoritarianism. Chicago: The University of Chicago Press, 1997.

LAPIDUS, Ira. A history of Islamic Societies. Cambridge: University Press Cambridge, 1988.

MARCUS, Michael. The Saint Has Been Stolen: Sanctity and Social Change in a Tribe of Eastern Morocco. In: American Ethnologist, Washington, v. 12, n. 3, p. 455-467, 1985.

MUNSON JR, Henry. Religion and Power in Morocco. New Haven and London: Yale University Press, 1993.

NABTI, Mehdi. Les Aissawa. Soufisme, musique et rituels de transe au Maroc. Paris: L'Harmattan, 2010.

NJOKU, Raphael Chijioke. Culture and customs of Morocco. Culture and customs of Africa. Westport: Greenwood Press 2006.

PETERS, Emrys. Baraka among the Bedouin of Cyrenaica. In: Bulletin British Society for Middle Eastern Studies, London, v. 16, n. 1, p. 5-13, 1989.

PINTO, Paulo Gabriel Hilu da Rocha. Islã: religião e civilização: uma abordagem antropológica. São Paulo: Editora Santuário, 2010.

Bodily Mediations: Self, Values and Experience in Syrian Sufism. In: HEISS, Johann (org.). Veranderung und Stabilitat: Normen und Werte in Islamischen Gesellschaften. Viena: Verlag der Oesterreichischen Akademie der Wissenschaften, 
2005.

Mystical Bodies. Ritual, Experience and the Embodiment of Sufism in Syria. Thesis (Ph. D.). Department of Anthropology, Boston University, 2002.

RASCH, Margaret. Bodies, Boundaries and Spirit Possession: Moroccan Women and the Revision of Tradition. Bielefeld: Transcript, 2000.

SCHIMMEL, Annemarie. Mystical dimensions of Islam. Chapel Hill: University of North Carolina Press, 1975.

TURNER, Victor. Peregrinações como processos sociais. Dramas, campos e metáforas: ação simbílica na sociedade humana. Niterói: EDUFF, 2008.

TRIMINGHAM, Spencer. The Sufi Orders in Islam. Oxford: Oxford University Press, 1971.

WEBER, Max. Economia e Sociedade. Fundamentos da sociologia compreensiva. Vol. 2. São Paulo: UnB, 2004.

História geral da economia. São Paulo: Mestre Jou, 1968.

. Os três tipos puros de dominação legítima. In: COHN, G. (Org.). Max Weber: Sociologia. São Paulo: Ática, 1982.

WESTERMARCK, Edward. Ritual and Beliefs in Morocco. New York: New Hyde Park, V. I \& II, 1968.

WHEELER, Brannon. Mecca and Eden: Ritual, Relics, and Territory in Islam. Chicago: University of Chicago Press, 2006. 